Transportation Research Forum

County-Level Impacts of Rail Line Abandonments: A Kansas Case Study

Author(s): James Sanderson and Michael W. Babcock

Source: Journal of the Transportation Research Forum, Vol. 44, No. 3 (Fall 2005), pp. 93-112

Published by: Transportation Research Forum

Stable URL: http://www.trforum.org/journal

The Transportation Research Forum, founded in 1958, is an independent, nonprofit organization of transportation professionals who conduct, use, and benefit from research. Its purpose is to provide an impartial meeting ground for carriers, shippers, government officials, consultants, university researchers, suppliers, and others seeking exchange of information and ideas related to both passenger and freight transportation. More information on the Transportation Research Forum can be found on the Web at www.trforum.org. 


\section{County-Level Impacts of Rail Line Abandonments: A Kansas Case Study}

This article describes the use of econometric panel data techniques to estimate the effects of rail line abandonments at the county level. The article presents the economic theory that indicates how abandonments will affect local communities. Data were collected on line abandonments and several economic measures for counties in Kansas. Panel data estimation techniques were used to provide estimates of the effects for rural, urban and metropolitan counties. Results indicate that abandonments produce an initial period of economic growth that may be temporary for some counties. Results also indicate that any adverse impacts appear with a time lag of a few years.

\section{by James Sanderson and Michael W. Babcock}

\section{INTRODUCTION}

\section{Statement of the Problem}

The railroad transportation sector is a key component of the U.S. economy. According to the Eno Transportation Foundation (Wilson 2002), $41.7 \%$ of total U.S. ton-miles of intercity freight were transported by rail in 2001. Another source, the Association of American Railroads (2004), indicates that in 2003, the railroads moved 7.4 million containers, 2.6 million trailers, and 20 million carloads of freight.
Despite the large quantities of freight being moved over the U.S. rail system, total rail mileage has been declining because of abandonment of lines. From 1975 to 2003, the top 10 states in track mileage lost $31.5 \%$ of their total track miles to abandonments (AAR 1978 and 2004). Table 1 lists the top 10 rail mileage states and their total miles of rail in 1975 and in 2003. As shown, state losses ranged from $21.4 \%$ of 1975 rail miles in California to $47.5 \%$ in Iowa. Because of the importance of the rail transportation system, abandonments represent a potentially significant problem for all of these states and for the entire U.S. economy.

Table 1: Railroad Miles-Top 10 States, 1975 and 2003

\begin{tabular}{lccc}
\hline State & 1975 Mileage & $\mathbf{2 0 0 3}$ Mileage & $\begin{array}{c}\text { Percent Change } \\
\mathbf{1 9 7 5 - 2 0 0 3}\end{array}$ \\
\hline Texas & 13,255 & 10,354 & $-21.9 \%$ \\
Illinois & 10,555 & 7,292 & $-30.9 \%$ \\
California & 7,291 & 5,733 & $-21.4 \%$ \\
Ohio & 7,506 & 5,203 & $-30.3 \%$ \\
Pennsylvania & 7,837 & 5,085 & $-35.1 \%$ \\
Kansas & 7,514 & 4,979 & $-33.7 \%$ \\
Minnesota & 7,294 & 4,631 & $-36.5 \%$ \\
Indiana & 6,357 & 4,237 & $-33.3 \%$ \\
Missouri & 6,010 & 4,089 & $-32.0 \%$ \\
Iowa & 7,547 & 3,963 & $-47.5 \%$ \\
\hline Total & 81,166 & 55,593 & $-31.5 \%$
\end{tabular}

Source: (1975) Association of American Railroads, Yearbook of Railroad Facts, 1978 edition, p.47. (2003) Association of American Railroads, Railroad Facts, 2004 edition, p.46. 
The state of Kansas provides a case study of significant rail line abandonments. Kansas currently ranks sixth in the nation for total miles of rail. Even so, the state lost $33.7 \%$ of its track mileage over the 1975-2003 period. Kansas is a major producer of commodities that are transported by rail. From 1998 to 2000, Kansas produced an average of more than one billion bushels of wheat, corn and sorghum annually (Kansas Agricultural Statistics Service 1998, 1999, and 2000).

With passage of the Staggers Rail Act in 1980, the regulatory environment became much less restrictive for firms wishing to abandon unprofitable lines and, since 1980, Kansas rail lines have been abandoned at a high rate. Over the period 1980 to 2001, the state lost a total of 1,972 miles of track, and 151 cities and towns lost all rail service (Kansas Department of Transportation 2002). Since 1980, the rate of loss in Kansas has been on the increase. From 1980 to 1989 , on average, 76 miles of track were abandoned and five cities lost rail service each year, compared to 102 miles of lost rail and eight abandoned cities each year from 1990 to 2001.

\section{Background and Objectives}

Declines in railroad transportation may occur for a number of reasons. Abandonments may be the result of technical substitution where a more efficient mode gains market share. Abandonments may also be associated with the depletion of natural resources. In these instances, the primary factor contributing to abandonments is a reduction in the demand for rail transport.

There are other factors that may contribute to abandonments. One factor is deferred maintenance. Maintenance costs for railroads are high relative to other costs, and rail firms can dramatically increase short-term profits by deferring maintenance and capital investment. ${ }^{1}$ However, as firms defer capital investments, their long-term ability to compete effectively is impaired. Firms may also have difficulties raising funds to make capital investments in rail lines because capital markets expect a relatively quick payback for these projects (Bitzan and Tolliver 2003). Imperfections in capital markets generate an intertemporal externality when the markets fail to evaluate the long-term value of assets such as upgraded railroad lines. Abandonments may also be related to a crosssubsidization of truck transportation by other road users. Numerous studies have found that trucks pay significantly less in user fees and taxes than the amount of road maintenance costs they occasion (Babcock et al. 2003).

The objectives of this paper are to present the economic theory that explains how rail line abandonments affect local communities and to develop a model that may be used to estimate the abandonment-related effects. Analysis in this article focuses on the situation in Kansas. An econometric panel data model is developed to estimate county-level effects, and the model is applied to Kansas counties. This effort represents the first application of econometric panel data techniques to the study of rail line abandonments. The econometric model should be suitable for estimating abandonment-related effects in any state or region and may be useful to researchers in other states that have lost large amounts of their rail systems.

\section{REVIEW OF LITERATURE}

\section{Effects on Income, Employment, and Related Measures}

An early study on the community-level economic impacts of rail line abandonment was published in 1974 by the Public Interest Economics Center (PIE-C 1974) as part of the analysis that went into the design of the CONRAIL system. The study modeled loss of rail service with a simultaneous equation general equilibrium approach, and for the majority of counties, PIE-C concluded that the income and employment changes would be small relative to the size of the affected economies. However, in extreme cases, real incomes were predicted to be reduced by as much as $3.3 \%$. Eusebio et al. (1992) applied the PIE-C procedures to Kansas counties for a 1992 Kansas Department of Transportation study and obtained similar results. 


\section{Effects of Rail to Truck Diversion on Highway Maintenance Costs}

Numerous studies have examined the abandonment-related highway maintenance impacts of rail-to-truck traffic diversion. Casavant and Lenzi (1990) developed a procedure that could be used to predict the effects of potential abandonments. The results of the study illustrated that the magnitude of truck traffic impacts will be heavily dependent on the structural characteristics of the roads that are affected. Denver Tolliver (1989 a and b) applied the Highway Performance Monitoring System (HPMS) to study the impacts of railto-truck diversion in North Dakota. Tolliver concluded that the collector and minor arterial highway system would be the most severely affected. Eusebio and Rindom (1991) used a network model developed by Chow (1985) to study rail-to-truck diversions. Their abandonment simulation resulted in an increase in average haul distances from production-area farms to local elevators from 4.7 miles to 7.0 miles.

A number of other studies have been conducted along similar lines. One should note Babcock et al. (2003), Babcock and Bunch (2002), Bitzan and Tolliver (2001), Tolliver and HDR Engineering (2000), Eriksen and Casavant (1998), Rindom et al. (1997), Lenzi et al. (1996), Russell et al. (1996), Russell et al. (1995), and Tolliver et al. (1994). In general, studies found that the road damage costs of railto-truck diversion will be heavily dependent on the structural characteristics of the roads affected.

Other studies indicate that user fee and tax revenue fall short of paying for associated pavement costs. The 1997 Federal Highway Cost Allocation Study (Federal Highway Administration 2000) indicates that vehicles in the weight class of 75,001 pounds to 80,000 pounds pay user fees and taxes amounting to $90 \%$ of the road damage costs they occasion, and heavier vehicles pay only $60 \%$ of their costs. One should also see Griffin (1982), Tolliver and HDR Engineering Inc. (2000), and Babcock et al. (2003) for similar results.

A few studies have examined other external costs resulting from rail-to-truck diversion. These costs involve increased accident rates on the highway system, increased noise pollution, and increased vehicle emissions. One should note Tolliver et al. (1994), Tolliver and HDR Engineering Inc. (2000), Forkenbrock (1999), and Babcock et al. (2003).

\section{ECONOMIC THEORY}

Economic theory provides a basis for explaining how firms and the communities they serve will be affected by termination of rail service. Rail line abandonment represents an increase in transportation costs to firms that are forced to shift to truck transport. A key factor will influence the significance of the change in costs. That factor is the size of transportation costs relative to a firm's total costs, because the greater this ratio, the greater will be the elasticity of transport demand.

Previous studies on the effects of abandonments have treated the increase in transportation costs as a decrease in the net output price received by the firm. Rail-using firms alter their production decisions when the price of their output changes. Altered production decisions mean that the communities served by these firms are affected. A community may experience reduced local spending, firm closures and lesser utilization of the production inputs it supplies. The prices of local goods and services may increase, and the rates paid for production inputs may decrease. Many of the following effects experienced by local communities are detailed in the PIE-C (1974) study.

\section{Effects on Competitive Firms}

For competitive profit-maximizing firms, the profit function and the output-supply function indicate the effects on firms that lose rail service. As mentioned, a transportation cost increase is equivalent to a decrease in the net price received by the firm. The firm profit function and supply function are positively related to output price, meaning that higher transportation costs lead to lower profits and reduced output.

A competitive firm's technology and industry characteristics will determine if it can continue to operate in the face of increased transportation costs. Firms that are receiving 
short-run economic profits will reduce factor utilization, while other firms will exit the industry.

\section{Effects on Firms with Market Power}

Rail-using firms may hold a degree of market power in the markets for their output. A monopolist's profit function indicates that as transportation costs increase the monopolist will reduce output, and as a consequence, the market price for output will increase.

Firms may also hold market power in the markets for factors. Monopsony wage-setting behavior is an example. When a single firm faces the entire market supply curve for labor, the marginal resource cost is higher than the wage and is no longer perfectly elastic at the marketdetermined wage as in a perfectly competitive labor market. In response to a decrease in the net price they receive, firms with market power in factor markets reduce their factor utilization, and they reduce the wage and rental rates they pay.

Economic theory predicts that the effects of rail line abandonments will be transmitted to communities through the firm-profitmaximization process. The effects of reduced incomes, reduced firm profits, and associated unemployment of production factors will be passed to local communities. Over time, these effects may be either magnified or mitigated by several factors.

\section{Impacts on Communities}

Communities are affected by reductions in income through a multiplier effect. Reductions in profits and factor payments lead to less local spending. Less local spending means that the incomes of all local firms may be reduced: not just the incomes of rail-using firms.

The wealth and incomes of numerous entities within a county may be affected by an abandonment. Rail is complementary to land, so an abandonment curtails the economic opportunities that the surrounding land can offer. A town or city that loses rail service is no longer an acceptable location alternative for firms that require rail transportation to compete effectively. Firms are pulled away from the area toward other locations, and reduced economic development and speculative opportunities are capitalized into lower land values. In addition, decreases in real and monetary incomes reduce the demand for real estate. Owners of land and other real estate see their wealth eroded by decreases in the value of their assets.

The community effects of rail line abandonment such as reduced incomes and wealth may be mitigated by several factors. First, declines in rail-using sectors are likely to be followed by growth in other sectors and at other locations. As rail is eliminated as a transport mode, growth in the trucking sector will occur. In addition, firms in other communities in the county that retain rail service will increase production as demand for their goods and services increases.

Land values may change as the result of an abandonment. As previously noted, rail service augments the utility of nearby land, and a county's supply of rail-augmented land decreases when rail lines are abandoned. This reduction may be represented as a leftward shift in the supply curve for rail-augmented land. When lines are abandoned, the value of the remaining rail-augmented land within the county increases. In some instances, this increase may mitigate the effects of an abandonment.

Another important factor that will mitigate the effects of line abandonments is the disbursement of transfer payments. Unemployment benefits, income maintenance payments, and other transfers will increase as workers lose their jobs, as wages and other factor payments are reduced, and as the profitability of firms declines. At the local level, these payments offset some of the reductions in income due to abandonments.

Using the counties in Kansas as a study area for the years 1980 to 2001, econometric panel data techniques were applied to test the validity of the economic theory of rail line abandonments and to quantify the actual effects. Econometric techniques provided estimates of any changes in county-level personal income, wages and salary disbursements, employment levels, and transfer payments related to rail line abandonments. 


\section{ECONOMIC AND EMPIRICAL MODELS}

Production and income at the county level is determined by the supply of and demand for the county's output. From a classical perspective, supply is determined by stocks of labor, capital, and natural resources, and by technology. Demand for output consists of consumption, investment, government purchases, and net exports. Changes in any of the supply or demand determinants will affect production. Other economic measures such as employment, factor payments, and transfer payments are directly linked to production and thus, are linked to supply and demand determinants.

Here, railroad transportation infrastructure is treated as a factor of production, and abandonments are modeled as a reduction in rail infrastructure. The empirical model of abandonments relies on classical economic foundations using measures or proxy measures for supply and demand determinants. Models include measures of income, factor payments, employment, and transfer payments as dependent variables while supply and demand determinants are included as the independent variables.

\section{The Empirical Models}

Data were found on several measures that would serve as dependent variables. The data included measures of personal income, transfer payments, wage and salary disbursements, and total full and part-time employment at the county level. The growth rates of these measures were used as dependent variables.

In the statistical models, rail line abandonment variables are expressed as the percent of county rail miles lost. It is known that traffic on lines scheduled for abandonment is often halted a year or more before the formal abandonment takes place. A lead of one year in the abandonment variable was used to capture this effect. Lags of abandonment variables were used to capture the effects that occur out to the fourth year following abandonment. Economic theory suggests that the abandonment variables should have negative effects on all of the dependent variables except the transfer payments variable where the effects should be positive.

Variables measuring county labor, and capital stocks were also identified. Labor stocks were modeled with a measure of county population. Capital stocks were represented by measures of the number of farm and nonfarm proprietorships. The expected signs for the coefficients of these variables are positive for all dependent variables except transfer payments growth because these variables represent increases in the productive capacity of the county. Government spending was represented with a measure of total government expenditures. The expected signs of government spending coefficients are also positive except in the case of transfer payments growth because government spending increases aggregate demand for a county's output. Last, product and factor demands were represented by a measure of regional production growth with the region being defined as the Plains region which includes the states of Iowa, Kansas, Minnesota, Missouri, Nebraska, North Dakota, and South Dakota. Regional production growth should have positive effects on the dependent variables except for transfer payments growth because it increases income and employment.

Empirical models take the following form: (1) $\mathrm{Y}_{\mathrm{it}}=\mathrm{b}_{0}+\mathrm{b}_{1}$ pmlead1 $_{\mathrm{it}}+\mathrm{b}_{2}$ pmilesab $_{\text {it }}+\mathrm{b}_{3}$ pmlag $1_{\text {it }}+b_{4}$ pmlag $_{\text {it }}+b_{5}$ pmlag $_{\text {it }}+b_{6}$ pmlag $_{\text {it }}$ $+b_{7}$ popgr $_{\text {it }}+b_{8}$ nfprppgr $_{\text {it }}+b_{9}$ fpropgr $_{\text {it }}+b_{10}$ rpgr $_{\text {it }}+\mathrm{b}_{11}$ govtgr $_{\text {it }}$

where:

$\mathrm{Y}_{\mathrm{it}}=$ dependent variable for county $\mathrm{i}$ at time $\mathrm{t}$,

$\mathrm{b}_{0}=$ constant term,

$\mathrm{b}_{1}-\mathrm{b}_{12}=$ coefficient estimates,

pmlead $1_{\text {it }}=$ percent of county rail miles abandoned with lead of one year for county $\mathrm{i}$ at time $\mathrm{t}$, pmilesab $_{\text {it }}=$ percent of county rail miles abandoned in current year for county i at time $\mathrm{t}$,

pmlag $1_{\mathrm{it}}=$ percent of county rail miles abandoned with lag of one year for county $i$ at time $t$, pmlag $2_{\text {it }}=$ percent of county rail miles abandoned with lag of two years for county $\mathrm{i}$ at time $\mathrm{t}$, 
pmlag $3_{\text {it }}=$ percent of county rail miles abandoned with lag of three years for county $\mathrm{i}$ at time t, pmlag $4_{\text {it }}=$ percent of county rail miles abandoned with lag of four years for county i at time t, $\operatorname{popgr}_{\text {it }}=$ county population growth rate for county i at time t,

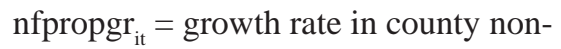
farm proprietorships for county i at time t, fpropgr $_{\text {it }}=$ growth rate in county farm proprietorships for county i at time t, $\operatorname{rpgr}_{\text {it }}=$ regional production growth rate, govtgr $_{\text {it }}=$ total government spending growth rate within county $i$ at time $t$, cons $_{\text {it }}=$ constant.

It was determined that econometric panel data techniques would be particularly suited to this project. First, panel data allow for the control of individual heterogeneity within the sample (Baltagi 2001). Controlling for the individual heterogeneity of counties will produce better quality estimates. Panel data also allows for study of the dynamics of an adjustment over time, and it is likely that abandonment-related effects will occur over a period of years.

Initial models where all counties were pooled and dummy variables were used to represent the types of counties, produced unsatisfactory statistical results. Thus, further controls for heterogeneity were initiated by estimating separate regressions for rural, urban, and metropolitan counties. Rural counties are counties that have no cities with populations greater than 2,500, are not adjacent to a metropolitan county, and are not within easy commuting distance to a county with 10,000 jobs or more. Metropolitan counties are central counties of metropolitan areas of at least one million people, or fringe counties of metropolitan areas of at least one million people. All other counties in the sample are classified as urban. For more details of the county classification system see Brown et. al. (1970).

\section{Data}

Data was obtained from a number of sources. County level income, employment, and other data were found in the Regional Economic Information System (REIS) 1969 - 2001 data set published by the U.S. Bureau of Economic Analysis (BEA), U.S. Department of Commerce (2003) (Table 2). All variables were converted to growth rates for estimation, and all monetary variables were adjusted for inflation to year 2000 dollars using the BEA national GDP implicit price deflator. The 2002 Official Kansas State Railroad Map (KDOT 2002 a) and The Kansas Rail Plan Update 2001-2002 (KDOT 2002 b) list rail line abandonments and mileages in Kansas. The locations of abandoned lines are also indicated on U.S. Geologic Survey (USGS 1997) topographic maps.

The study period chosen includes the years from 1980 to 2001. A significant structural change in the railroad industry occurred in 1980 with passage of The Staggers Rail Act. For this reason, 1980 was chosen as the starting period for this study. All the data required for estimation were available for the years up to

Table 2: REIS Data Set, County-Level Variables

$$
\begin{aligned}
& \text { Dependent Variables } \\
& \text { Personal Income } \\
& \text { Transfer Payments } \\
& \text { Wage and Salary Disbursements } \\
& \text { Total Full- and Part-Time Employment } \\
& \text { Independent Variables } \\
& \text { Population } \\
& \text { The Number of Non-Farm Proprietorships } \\
& \text { The Number of Farm Proprietorships } \\
& \text { Regional Product Growth } \\
& \text { Total Government Spending in the County }
\end{aligned}
$$


and including 2001, so this year was chosen as the last year of the study period.

Different types of counties in Kansas exhibit different patterns of growth, and their economies are based on different markets. The Rural-Urban Continuum Code (RUCC) classification scheme used by the U.S. Department of Agriculture Economic Research Service (Brown et al. 1970) was used to classify the different types of counties in Kansas.

\section{EMPIRICAL RESULTS}

Tables 3, 4, and 5 give the empirical results. The results for the rural counties are found in Table 3, and the results for the urban and metropolitan counties are found in Tables 4 and 5. The variables that have a p-value are $10 \%$ or less are considered statistically significant. Random effects models were used whenever possible, and the Hausman specification test was used to determine if correlation between the regressors and error terms would invalidate random effects results. Random effects results were tested for autocorrelation problems with the Wooldridge test, and in three instances, the Prais-Winsten procedure was used to correct for autocorrelation. Individual random effects were evaluated with the use of the Breusch and Pagan LM test. In seven instances, individual effects were found insignificant, and OLS was used. Of the seven instances where OLS was used, three models report robust standard errors to correct for heteroskedasticity problems as indicated by the Breusch-Pagan/Cook-Weisberg test.

\section{Rural Counties}

None of the abandonment variables have statistical significance in the model of real personal income growth rate or the model of total full- and part-time employment growth rate. However, significant coefficients do appear in other models. The two significant abandonment coefficients in the real transfer payment growth rate model at year zero and lag one are negative; representing a reduction in the growth rate of transfer payments. Positive and significant abandonment coefficients in the real wage and salary disbursements growth rate model for the lead one year and the lag one year indicate that initially abandonment is associated with an increase in wage growth. It should be noted that the positive year zero coefficient also approaches the $10 \%$ significance level. The negative and significant coefficient that appears at lag four in the model of real wage and salary growth rate represents an adverse impact to the county economy in the longer run.

The estimates for the rural counties lead to an important question. How is it possible that some coefficients indicate positive economic impacts associated with abandonments? These results are plausible according to economic theory. Theory predicts that growth in the trucking sector and growth at locations that retain rail service will follow abandonments. It was also found that individual random effects were significant in all rural county models. This is in contrast to models for other counties. The individual effects indicate that the rural counties have more unobserved heterogeneity than the urban or metropolitan counties where the individual effects are less likely to be significant.

It should be noted that the negative coefficient at lag four in the real wage and salary growth rate model represents an adverse effect. The time lag suggests that while the initial period following an abandonment may be characterized by economic growth, some of this growth may be temporary, or it may suggest that adverse effects begin to appear several years after an abandonment.

\section{Urban Counties}

Table 4 contains the coefficient estimates and associated statistics for urban counties. Statistically significant abandonment coefficients are found in only three instances. The first and third lag coefficients for the real wage and salary growth rate model are significant and positive, and the third lag coefficient for total full- and part-time employment growth rate model is also significant and positive. In these instances of significance, the coefficients indicate beneficial effects on the county economy.

As with results for rural counties, abandonments in urban counties appear to be 


\section{Table 3: Coefficient Estimates for Rural Counties}

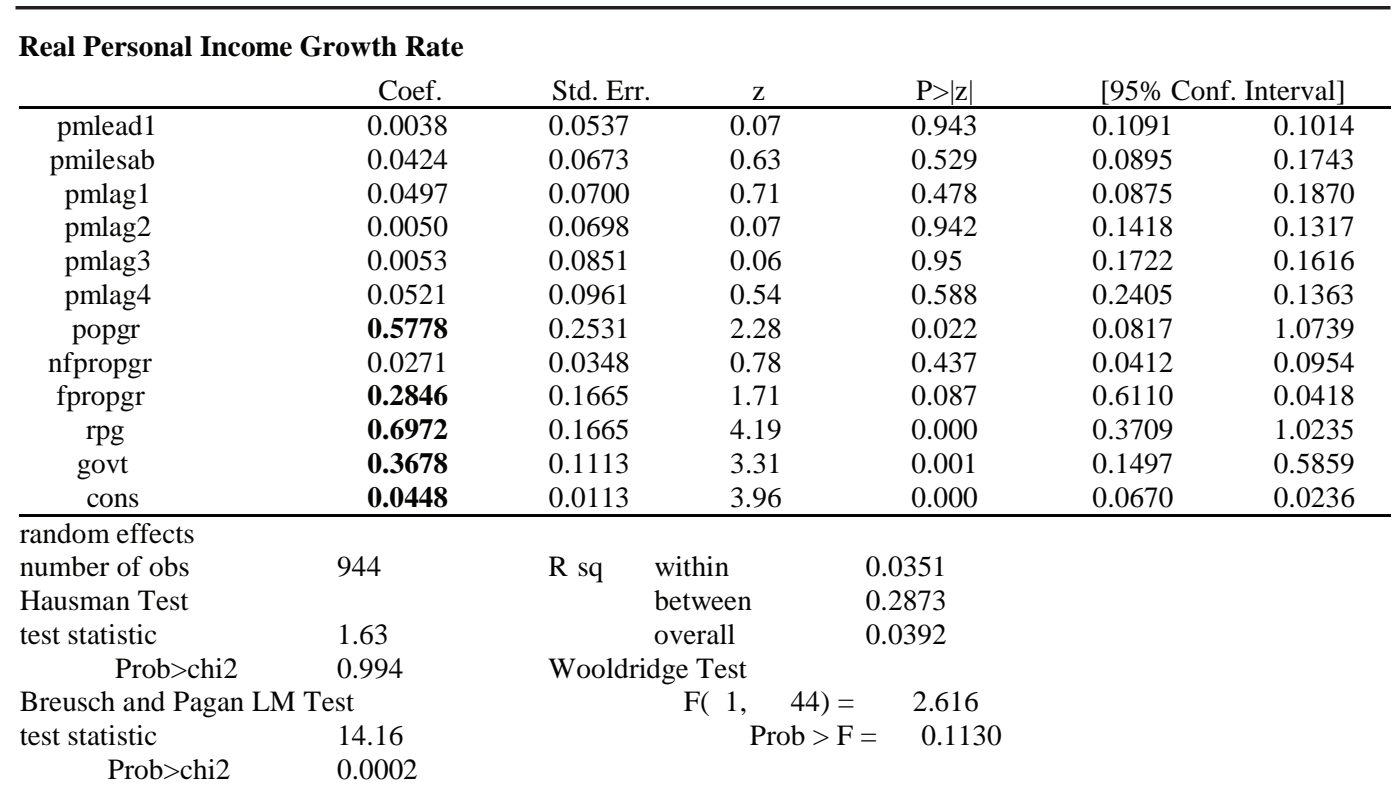

Real Transfer Payments Growth Rate

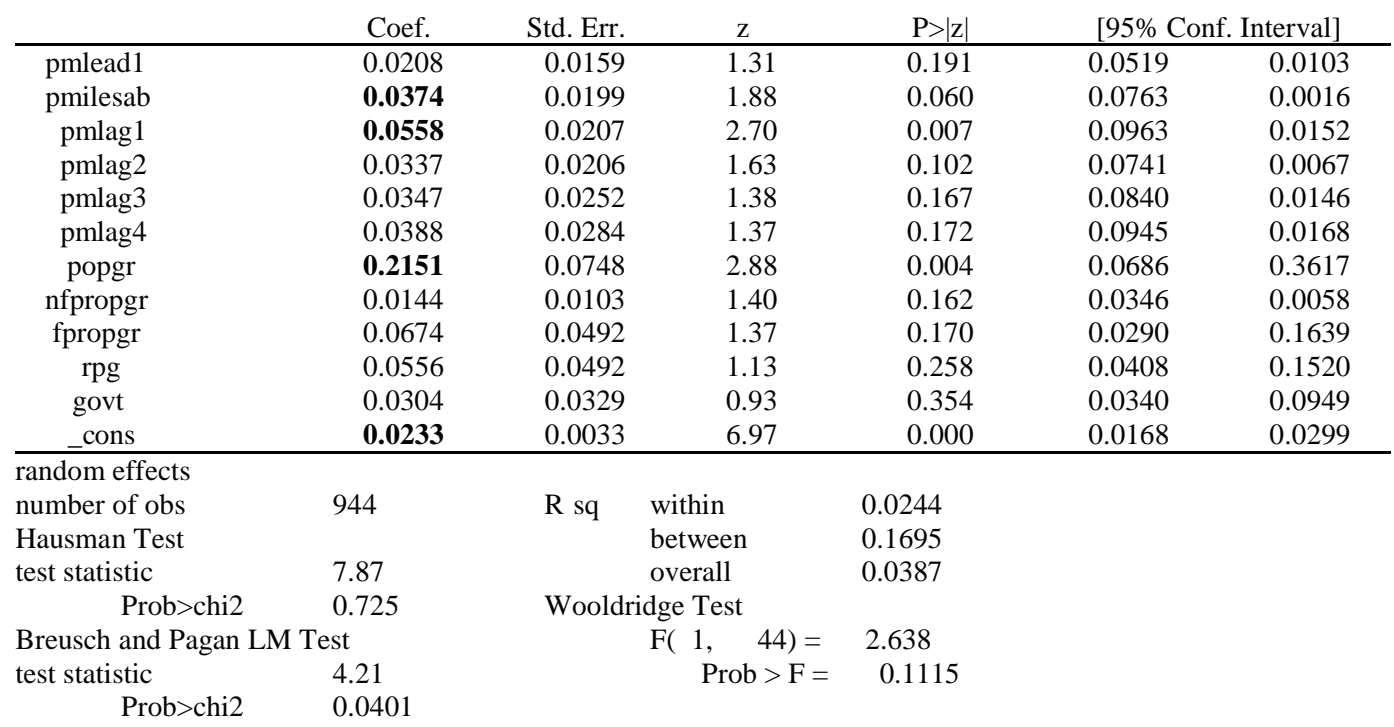


Rail Line Abandonment

\section{Table 3: Coefficient Estimates for Rural Counties (continued)}

Real W age and Salary Disbursements Growth R ate

\begin{tabular}{|c|c|c|c|c|c|c|}
\hline & Coef. & Std. Err. & \multirow{2}{*}{$\frac{z}{2.06}$} & \multirow{2}{*}{$\frac{P>|z|}{0.039}$} & \multicolumn{2}{|c|}{ [95\% Conf. Interval] } \\
\hline pmleadl & 0.0413 & 0.0201 & & & 0.0020 & 0.0806 \\
\hline pmilesab & 0.0406 & 0.0251 & 1.62 & 0.106 & 0.0086 & 0.0899 \\
\hline pmlag1 & 0.0518 & 0.0262 & 1.98 & 0.048 & 0.0005 & 0.1031 \\
\hline pmlag2 & 0.0129 & 0.0261 & 0.49 & 0.622 & 0.0382 & 0.0640 \\
\hline pmlag3 & 0.0403 & 0.0318 & 1.27 & 0.205 & 0.0220 & 0.1027 \\
\hline pmlag4 & 0.0735 & 0.0359 & 2.05 & 0.041 & 0.1439 & 0.0031 \\
\hline popgr & 0.5370 & 0.0946 & 5.68 & 0.000 & 0.3517 & 0.7224 \\
\hline nfpropgr & 0.0003 & 0.0130 & 0.02 & 0.984 & 0.0258 & 0.0252 \\
\hline fpropgr & 0.0829 & 0.0622 & 1.33 & 0.183 & 0.2048 & 0.0391 \\
\hline rpg & 0.2220 & 0.0622 & 3.57 & 0.000 & 0.1001 & 0.3439 \\
\hline govt & 0.2450 & 0.0416 & 5.89 & 0.000 & 0.1635 & 0.3265 \\
\hline cons & 0.0153 & 0.0042 & 3.61 & 0.000 & 0.0236 & 0.0070 \\
\hline \multicolumn{7}{|c|}{ random effects } \\
\hline number of ol & \multicolumn{2}{|c|}{944} & \multirow[t]{2}{*}{$\mathrm{R} s q$} & \multirow{2}{*}{$\begin{array}{l}\text { within } \\
\text { between }\end{array}$} & 0.0941 & \\
\hline Hausman Te & & & & & 0.3594 & \\
\hline test statistic & \multicolumn{2}{|c|}{2.01} & \multicolumn{2}{|c|}{ overall } & 0.1023 & \\
\hline \multicolumn{2}{|c|}{ Prob $>$ chi2 } & & \multicolumn{2}{|c|}{ Wooldridge T est } & & \\
\hline \multicolumn{3}{|c|}{ B reusch and Pagan LM Test } & \multirow{2}{*}{\multicolumn{2}{|c|}{ 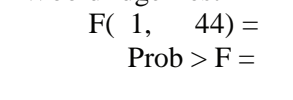 }} & \multirow{2}{*}{$\begin{array}{l}1.195 \\
0.2803\end{array}$} & \\
\hline \multicolumn{2}{|c|}{ Prob>chi2 } & & & & & \\
\hline
\end{tabular}

Total Full and Part Time E mployment Growth R ate

\begin{tabular}{ccccccc}
\multicolumn{3}{c}{$\begin{array}{c}\text { Panel Corrected } \\
\text { Std. Err. }\end{array}$} & $\mathrm{z}$ & $\mathrm{P}>|\mathrm{z}|$ & \multicolumn{2}{c}{ [95\% Conf. Interval] } \\
\hline pmlead1 & 0.0109 & 0.0092 & 1.19 & 0.235 & 0.0071 & 0.0290 \\
pmilesab & 0.0191 & 0.0117 & 1.63 & 0.104 & 0.0039 & 0.0420 \\
pmlag1 & 0.0064 & 0.0130 & 0.49 & 0.622 & 0.0191 & 0.0319 \\
pmlag2 & 0.0018 & 0.0126 & 0.15 & 0.884 & 0.0228 & 0.0265 \\
pmlag3 & 0.0041 & 0.0162 & 0.26 & 0.799 & 0.0359 & 0.0276 \\
pmlag4 & 0.0223 & 0.0160 & 1.40 & 0.162 & 0.0538 & 0.0090 \\
popgr & 0.1237 & 0.1087 & 1.14 & 0.255 & 0.0894 & 0.3367 \\
nfpropgr & 0.2688 & 0.0171 & 15.7 & 0.000 & 0.2353 & 0.3024 \\
fpropgr & 0.2984 & 0.1119 & 2.67 & 0.008 & 0.0791 & 0.5178 \\
rpg & 0.0722 & 0.1371 & 0.53 & 0.599 & 0.1966 & 0.3409 \\
govt & 0.0585 & 0.0385 & 1.52 & 0.128 & 0.0169 & 0.1339 \\
cons & 0.0051 & 0.0090 & 0.57 & 0.570 & 0.0228 & 0.0126 \\
\hline
\end{tabular}

Prais W insten Procedure

number of obs 944

Wald Test

test statistic

388.75

R sq $\quad 0.6416$

Prob $>$ chi $2 \quad 0$ 
Table 4: Coefficient Estimates for Urban Counties

Real Personal Income Growth Rate

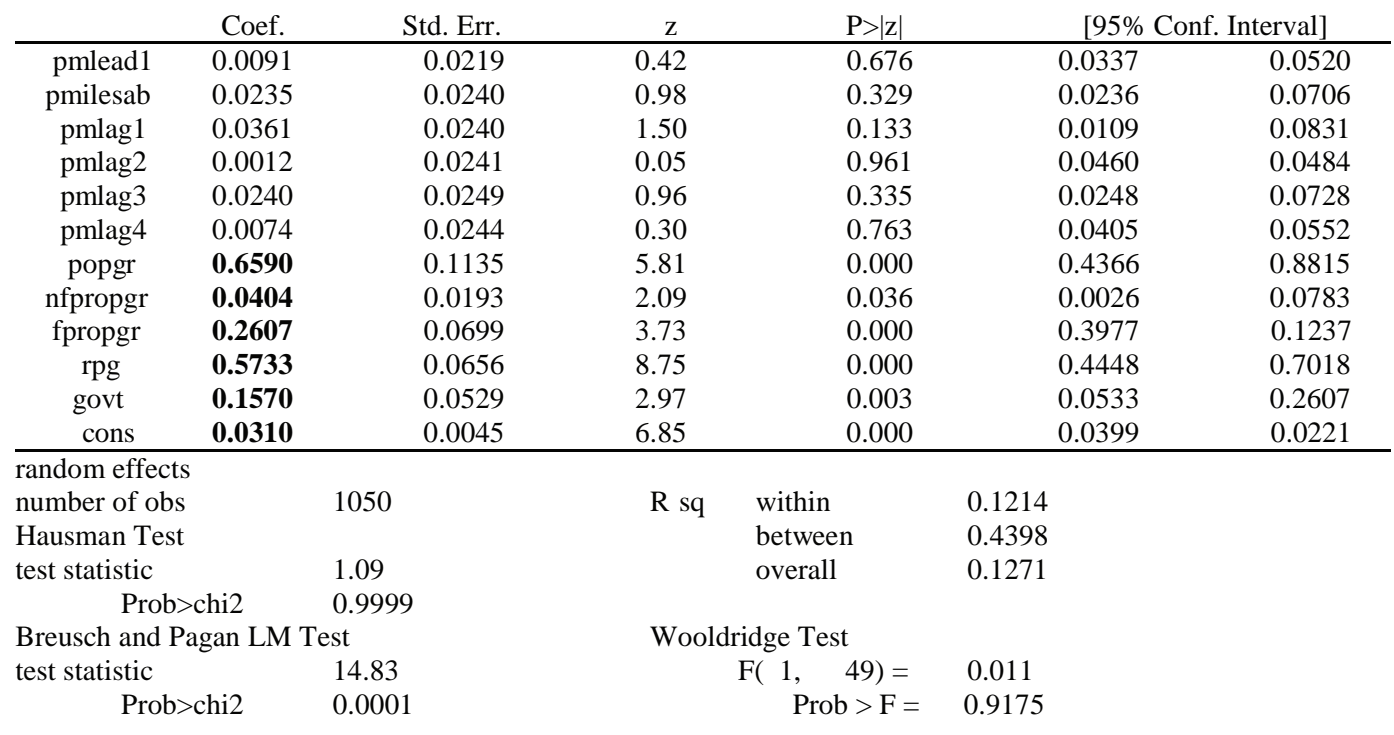

Real Transfer Payments Growth Rate

\begin{tabular}{|c|c|c|c|c|c|c|}
\hline & Coef. & $\begin{array}{c}\text { nel Correc } \\
\text { Std. Err. }\end{array}$ & Z & $P>|z|$ & \multicolumn{2}{|c|}{ [95\% Conf. Interval] } \\
\hline pmleadl & 0.0121 & 0.0135 & 0.9 & 0.370 & 0.0385 & 0.0143 \\
\hline pmilesab & 0.0219 & 0.0158 & 1.38 & 0.167 & 0.0529 & 0.0092 \\
\hline pmlag1 & 0.0015 & 0.0155 & 0.10 & 0.922 & 0.0289 & 0.0319 \\
\hline pmlag2 & 0.0145 & 0.0160 & 0.91 & 0.364 & 0.0458 & 0.0168 \\
\hline pmlag3 & 0.0119 & 0.0162 & 0.74 & 0.461 & 0.0437 & 0.0198 \\
\hline pmlag4 & 0.0171 & 0.0153 & 1.12 & 0.262 & 0.0467 & 0.0128 \\
\hline popgr & 0.4450 & 0.1354 & 3.29 & 0.001 & 0.1796 & 0.7104 \\
\hline nfpropgr & 0.0380 & 0.0322 & 1.18 & 0.239 & 0.1012 & 0.0252 \\
\hline fpropgr & 0.1114 & 0.1719 & 0.65 & 0.517 & 0.2256 & 0.4483 \\
\hline $\mathrm{rpg}$ & 0.1684 & 0.1873 & 0.90 & 0.368 & 0.5354 & 0.1986 \\
\hline govt & 0.0451 & 0.0701 & 0.64 & 0.520 & 0.1825 & 0.0923 \\
\hline cons & 0.0379 & 0.0122 & 3.10 & 0.002 & 0.0140 & 0.0618 \\
\hline
\end{tabular}

Prais W insten Procedure

number of obs

W ald Test

test statistic Prob>chi2 $\quad 0.0135$

\section{0}

23.83

R sq $\quad 0.0914$ 
Rail Line Abandonment

\section{Table 4: Coefficient Estimates for Urban Counties (continued)}

Real W age and Salary Disbursements Growth R ate

Robust

\begin{tabular}{ccccccc} 
& Coef. & Std. Err. & $\mathrm{z}$ & $\mathrm{P}>|\mathrm{z}|$ & {$[95 \%$ Conf. Interval] } \\
\hline pmlead1 & 0.0196 & 0.0138 & 1.42 & 0.157 & 0.0075 & 0.0467 \\
pmilesab & 0.0083 & 0.0177 & 0.47 & 0.640 & 0.0264 & 0.0430 \\
pmlag1 & 0.0251 & 0.0149 & 1.68 & 0.094 & 0.0043 & 0.0544 \\
pmlag2 & 0.0233 & 0.0157 & 1.48 & 0.140 & 0.0077 & 0.0543 \\
pmlag3 & 0.0532 & 0.0136 & 3.92 & 0.000 & 0.0266 & 0.0799 \\
pmlag4 & 0.0028 & 0.0147 & 0.19 & 0.850 & 0.0260 & 0.0316 \\
popgr & 1.2945 & 0.2627 & 4.93 & 0.000 & 0.7790 & 1.8100 \\
nfpropgr & 0.0135 & 0.0273 & 0.49 & 0.622 & 0.0401 & 0.0670 \\
fpropgr & 0.1406 & 0.0622 & 2.26 & 0.024 & 0.2627 & 0.0184 \\
rpg & 0.3038 & 0.0523 & 5.81 & 0.000 & 0.2013 & 0.4064 \\
govt & 0.1352 & 0.0684 & 1.98 & 0.048 & 0.0009 & 0.2695 \\
cons & 0.0146 & 0.0034 & 4.27 & 0.000 & 0.0214 & 0.0079 \\
\hline
\end{tabular}

OLS with robust standard errors

number of obs $\quad 1050$

$\begin{array}{cl}\mathrm{F}(11,1038) & 18.13 \\ \text { Prob }>\mathrm{F} & 0.0000\end{array}$

R sq $\quad 0.1934$

Total Full and Part Time Employment Growth Rate

\begin{tabular}{|c|c|c|c|c|c|c|}
\hline & Coef. & $\begin{array}{l}\text { Robust } \\
\text { Std. Err. }\end{array}$ & z & $P>|z|$ & \multicolumn{2}{|c|}{ [95\% Conf. Interval] } \\
\hline pmlead1 & 0.0117 & 0.0082 & 1.42 & 0.156 & 0.0045 & 0.0278 \\
\hline pmilesab & 0.0004 & 0.0099 & 0.04 & 0.969 & 0.0191 & 0.0198 \\
\hline pmlag1 & 0.0166 & 0.0116 & 1.43 & 0.153 & 0.0062 & 0.0393 \\
\hline pmlag2 & 0.0081 & 0.0091 & 0.89 & 0.375 & 0.0098 & 0.0259 \\
\hline pmlag3 & 0.0302 & 0.0091 & 3.33 & 0.001 & 0.0124 & 0.0480 \\
\hline pmlag4 & 0.0015 & 0.0120 & 0.13 & 0.899 & 0.0251 & 0.0221 \\
\hline popgr & 0.7970 & 0.1285 & 6.20 & 0.000 & 0.5448 & 1.0492 \\
\hline nfpropgr & 0.1988 & 0.0169 & 11.7 & 0.000 & 0.1657 & 0.2319 \\
\hline fpropgr & 0.0819 & 0.0349 & 2.35 & 0.019 & 0.0134 & 0.1504 \\
\hline $\mathrm{rpg}$ & 0.1988 & 0.0327 & 6.07 & 0.000 & 0.1346 & 0.2631 \\
\hline govt & 0.0320 & 0.0354 & 0.91 & 0.365 & 0.0374 & 0.1014 \\
\hline cons & 0.0076 & 0.0022 & 3.41 & 0.001 & 0.0119 & 0.0032 \\
\hline
\end{tabular}

OLS with robust standard errors

number of obs $\quad 1050$

$F(11,1038) \quad 28.03$

R sq $\quad 0.419$

Prob $>\mathrm{F} \quad 0.0000$ 
associated with beneficial effects. The significant coefficients may, in part, be reflecting the shift to truck transportation; a more labor intensive mode. This would explain the growth in wages and salaries and the growth in total full and part-time employment.

Another important factor may involve the growth predicted for regions that retain rail service. Most large terminal elevator transshipment facilities are located in urbansized counties. It is known that farmers are increasingly utilizing semi-tractor trailer trucks to transport grain longer distances to terminal elevators (Babcock et al. 2002). Theory predicts that rail line abandonments result in lower prices paid for grain at local country elevators. The lower prices provide greater incentives for farmers to bypass local country elevators and haul their grain directly to large terminal facilities that are more likely to be located in urban counties. For these reasons, abandonments may be associated with greater levels of growth and lesser decline in the urban counties.

\section{Metropolitan Counties}

Metropolitan county estimates are presented in Table 5. The model of real personal income growth rate for metropolitan counties contains two positive and significant abandonment coefficients; one at lag one and one at lag three. However, at lag four, the real personal income coefficient is negative and significant. Similar to previous results, a negative effect appears with a time lag of several years.

The largest abandonment coefficients found in any of the models are in the model of real transfer payments growth rate for the metropolitan counties. At lags of two and three years, large positive and significant coefficients indicate relatively large adverse impacts associated with abandonments in these counties.

The model of total full- and part-time employment growth rate contains a significant positive coefficient for the year of abandonment. Again, the coefficient may be reflecting the shift from rail to truck transport and the increase in production at locations that retain rail service.

\section{Control Variables}

The signs and magnitudes of many of the control variable coefficients are as expected. According to economic theory, an increase in population or greater demand for goods and services will have a positive effect on production. Estimates here confirm that this is the case. Population growth rate coefficients are positive and statistically significant in all but one of the rural, urban, and metropolitan county models. In general, population growth rate coefficients are the largest of any of the control variable coefficients.

Growth in the number of non-farm proprietorships has statistically significant, positive effects on total full-time and parttime employment growth in rural, urban and metropolitan counties. Also, the variable has a significant positive effect on personal income growth in the urban counties.

Coefficients for the growth rate in the number of farm proprietorships indicate mostly adverse county-level impacts, but in a few instances, the impacts are positive. The number of farm proprietorships has negative effects on real personal income growth in all three types of counties, and it reduces wage and salary growth in the urban counties. Positive impacts include increases in employment in rural and urban counties. The negative coefficients may be reflecting the economic hardships faced by agricultural producers, or another explanation is that they are reflecting the increasing size of individual farms.

The regional product growth rate variable generally has relatively large coefficients, and significant coefficients represent beneficial impacts at the county level. In models where it is significant, it is positively related to the income, wage and salary, and employment variables and negatively related to transfer payments.

Significant coefficients for government spending also indicate beneficial impacts with positive coefficients for the income, wage and salary, and employment equations. Government spending, however, appears to have no effect on transfer payments growth rates. 
Rail Line Abandonment

\section{Table 5: Coefficient Estimates for Metropolitan Counties}

Real Per sonal Income Growth Rate

\begin{tabular}{clccccc} 
& Coef. & Std. Err. & $Z$ & $P>|z|$ & \multicolumn{1}{c}{ [95\% Conf. Interval] } \\
\hline pmlead1 & 0.0273 & 0.0357 & 0.76 & 0.446 & 0.0977 & 0.0432 \\
pmilesab & 0.0329 & 0.0384 & 0.86 & 0.392 & 0.0429 & 0.1087 \\
pmlag1 & 0.1037 & 0.0380 & 2.73 & 0.007 & 0.0287 & 0.1788 \\
pmlag2 & 0.0146 & 0.0390 & 0.37 & 0.709 & 0.0625 & 0.0916 \\
pmlag3 & 0.0858 & 0.0374 & 2.29 & 0.023 & 0.0120 & 0.1596 \\
pmlag4 & 0.0614 & 0.0364 & 1.69 & 0.094 & 0.1334 & 0.0105 \\
popgr & 0.8152 & 0.1359 & 6.00 & 0.000 & 0.5471 & 1.0833 \\
nfpropgr & 0.0037 & 0.0264 & 0.14 & 0.890 & 0.0485 & 0.0558 \\
fpropgr & 0.2040 & 0.0630 & 3.24 & 0.001 & 0.3283 & 0.0797 \\
rpg & 0.3589 & 0.0607 & 5.91 & 0.000 & 0.2391 & 0.4786 \\
govt & 0.1667 & 0.0540 & 3.09 & 0.002 & 0.0602 & 0.2732 \\
cons & 0.0120 & 0.0046 & 2.57 & 0.011 & 0.0211 & 0.0028 \\
\hline
\end{tabular}

OLS

$\begin{array}{ll}\text { number of obs } & 189 \\ \mathrm{~F}(11,1038) & 12.52\end{array}$

Prob $>F \quad 0.0000$

B reusch Pagan / Cook W eisberg Test

chi $2(1)=1.26$

Prob $>$ chi2 $=0.2619$

Real Transfer Payments Growth Rate

\begin{tabular}{cllllll} 
& Coef. & Std. Err. & $\mathrm{z}$ & $\mathrm{P}>|\mathrm{z}|$ & \multicolumn{2}{c}{$[95 \%$ Conf. Interval] } \\
\hline pmlead1 & 0.0325 & 0.0526 & 0.62 & 0.538 & 0.1363 & 0.0714 \\
pmilesab & 0.0347 & 0.0566 & 0.61 & 0.540 & 0.0770 & 0.1465 \\
pmlag1 & 0.0268 & 0.0560 & 0.48 & 0.634 & 0.1374 & 0.0839 \\
pmlag2 & 0.1145 & 0.0576 & 1.99 & 0.048 & 0.0009 & 0.2282 \\
pmlag3 & 0.1342 & 0.0551 & 2.43 & 0.016 & 0.0254 & 0.2430 \\
pmlag4 & 0.0420 & 0.0537 & 0.78 & 0.436 & 0.1480 & 0.0641 \\
popgr & 0.7367 & 0.2003 & 3.68 & 0.000 & 0.3415 & 1.1320 \\
nfpropgr & 0.0402 & 0.0389 & 1.03 & 0.303 & 0.1171 & 0.0366 \\
fpropgr & 0.0180 & 0.0928 & 0.19 & 0.847 & 0.2012 & 0.1652 \\
rpg & 0.3201 & 0.0895 & 3.58 & 0.000 & 0.4966 & 0.1435 \\
govt & 0.0792 & 0.0796 & 1.00 & 0.321 & 0.2362 & 0.0778 \\
cons & 0.0462 & 0.0069 & 6.73 & 0.000 & 0.0326 & 0.0597 \\
\hline
\end{tabular}

OLS

number of obs $\quad 189$

$F(11,1038) \quad 3.79$

Adj R sq

0.1404

Prob $>F \quad 0.0001$

B reusch Pagan / Cook W eisberg Test

$\operatorname{chi} 2(1)=0.71$

Prob $>$ chi2 $=0.3998$ 
Table 5: Coefficient Estimates for Metropolitan Counties (continued)

Real W age and Salary Disbursements Growth R ate

\begin{tabular}{ccccccc}
\multicolumn{3}{c}{$\begin{array}{c}\text { Panel Corrected } \\
\text { Std. Err. }\end{array}$} & $\mathrm{t}$ & $\mathrm{P}>|\mathrm{t}|$ & \multicolumn{2}{c}{ [95\% Conf. Interval] } \\
\hline pmlead1 & 0.0694 & 0.0520 & 1.33 & 0.183 & 0.0326 & 0.1714 \\
pmilesab & 0.0796 & 0.0561 & 1.42 & 0.156 & 0.0303 & 0.1895 \\
pmlag1 & 0.0340 & 0.0535 & 0.63 & 0.526 & 0.0709 & 0.1388 \\
pmlag2 & 0.0211 & 0.0552 & 0.38 & 0.703 & 0.0872 & 0.1293 \\
pmlag3 & 0.0831 & 0.0537 & 1.55 & 0.122 & 0.0222 & 0.1883 \\
pmlag4 & 0.0341 & 0.0503 & 0.68 & 0.498 & 0.1327 & 0.0646 \\
popgr & 1.1771 & 0.1997 & 5.89 & 0.000 & 0.7857 & 1.5685 \\
nfpropgr & 0.0301 & 0.0590 & 0.51 & 0.610 & 0.1457 & 0.0855 \\
fpropgr & 0.2317 & 0.1549 & 1.50 & 0.135 & 0.5353 & 0.0719 \\
rpg & 0.1698 & 0.1627 & 1.04 & 0.296 & 0.1490 & 0.4887 \\
govt & 0.2890 & 0.0879 & 3.29 & 0.001 & 0.1167 & 0.4612 \\
cons & 0.0134 & 0.0111 & 1.21 & 0.227 & 0.0353 & 0.0084 \\
\hline
\end{tabular}

Prais W insten Procedure number of obs

Wald Test

test statistic 189

$\begin{array}{ll}\text { Probschi2 } & 92.08 \\ & 0.0000\end{array}$

\section{R sq $\quad 0.2867$}

Prob $>$ chi2 $\quad 0.0000$

Total Full and Part Time E mployment Growth R ate

\begin{tabular}{ccccccc} 
& Coef. & Std. Err. & $\mathrm{z}$ & $\mathrm{P}>|\mathrm{z}|$ & \multicolumn{2}{c}{$[95 \%$ Conf. Interval] } \\
\hline pmlead1 & 0.0380 & 0.0314 & 1.21 & 0.227 & 0.0239 & 0.0999 \\
pmilesab & 0.0688 & 0.03375 & 2.04 & 0.043 & 0.0022 & 0.1354 \\
pmlag1 & 0.0177 & 0.0334 & 0.53 & 0.596 & 0.0481 & 0.0837 \\
pmlag2 & 0.0018 & 0.0343 & 0.05 & 0.959 & 0.0695 & 0.0659 \\
pmlag3 & 0.0069 & 0.0328 & 0.21 & 0.833 & 0.0579 & 0.0717 \\
pmlag4 & 0.0074 & 0.0320 & 0.23 & 0.816 & 0.0706 & 0.0557 \\
popgr & 0.9316 & 0.1194 & 7.81 & 0.000 & 0.6960 & 1.1671 \\
nfpropgr & 0.1585 & 0.0232 & 6.83 & 0.000 & 0.1127 & 0.2043 \\
fpropgr & 0.0815 & 0.0553 & 1.47 & 0.143 & 0.1907 & 0.0277 \\
rpg & 0.1113 & 0.0533 & 2.09 & 0.038 & 0.0061 & 0.2165 \\
govt & 0.1538 & 0.0474 & 3.24 & 0.001 & 0.0603 & 0.2474 \\
cons & 0.0091 & 0.0040 & 2.23 & 0.027 & 0.0172 & 0.0011 \\
\hline
\end{tabular}

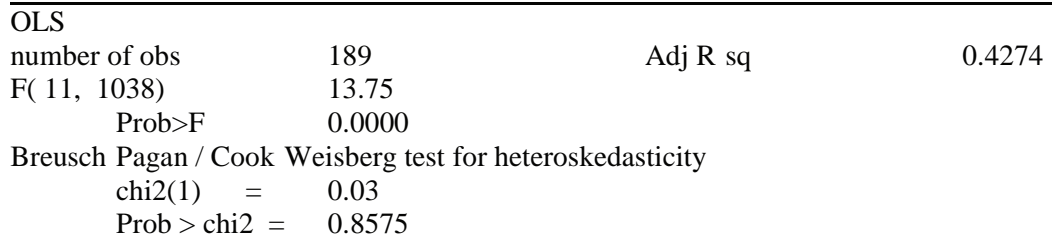




\section{Magnitude of Dependent Variable Effects}

In addition to identifying statistically significant coefficients, it is important to determine the magnitude of the estimated effects. Table 6 lists the 1997 to 2001 five-year average values and growth rates of the dependent variables. Multiplication of the five-year average values by the appropriate coefficients and by an abandonment percentage can give annual dollar value or employment level increases or decreases for an average rural, urban, or metropolitan county. For example, the average value of real wage and salary disbursements for a rural county is $\$ 30,815,130$ as given in Table 6. Table 3 lists the coefficient for the percent of miles abandoned lead 1 (pmlead1) variable in the real wage and salary model for rural counties as 0.0413 . An assumption that the rural county loses $20 \%$ of its rail miles (the average loss over the period in the data set was $18.1 \%$ ) to an abandonment would give the following result: (2) Average Value x Coefficient Estimate x $20 \%=$ Real Wage and Salary Effect (\$) or $\$ 30,815,130 \times 0.0413 \times .20=\$ 254,533$.

The rural county would experience an increasein annual wage and salary disbursements of $\$ 254,533$ the year before the abandonment. The wage and salary effects for the lag one year equal \$319,245 (\$30,815,130 x 0.0518 x 0.20), and four years following the abandonment, the rural county would experience a reduction of $\$ 452,982(\$ 30,815,130 \times-0.0735 \times 0.20)$ in annual wages and salaries. Thus wage and salary disbursements would increase by $\$ 120,796$ for the four year period $(\$ 254,533+$ $\$ 319,245$ - \$452,982).

Similar calculations may be performed for the other dependent variables. Table 7 lists the dollar value and employment effects associated with a loss of $20 \%$ of rail miles for average rural, urban, and metropolitan counties. In response to losing $20 \%$ of its rail miles, the average rural county would experience a reduction of $\$ 142,645$ in annual transfer payments during year zero and a further reduction of $\$ 212,868$ at lag year one. An average urban county losing $20 \%$ of its rail miles would experience increases in annual wages and salaries of \$1,043,285 and $\$ 2,211,264$ in lag years one and three and an increase in employment of 73 jobs in lag year three. After the loss of $20 \%$ of rail miles in the average metropolitan county, annual real personal income will increase by $\$ 104,783,001$ and again by $\$ 86,696,061$ in years one and three following the abandonment, and it will fall by $\$ 62,041,237$ in the fourth year. The net gain for the four year period is $\$ 129.5$ million. In the average metropolitan county, real transfer payments will increase by $\$ 11,906,802$ and

Table 6: Average Values for Dependent Variables, 1997-2001

\begin{tabular}{l}
\hline Rural Counties \\
Real Personal Income \\
Real Transfer Payments \\
Real Wage and Salary Disbursements \\
Total Full- and Part-Time Employment
\end{tabular}

$\underline{\text { Urban Counties }}$

Real Personal Income

Real Transfer Payments

Real W age and Salary Disbursements

Total Full- and Part-Time Employment

M etropolitan Counties

Real Personal Income

Real Transfer Payments

Real W age and Salary Disbursements

Total Full- and Part-Time Employment

\begin{tabular}{rc} 
A verage V alue & A verage Growth R ate \\
\cline { 2 - 2 }$\$ 101,104,800$ & $0.17 \%$ \\
$\$ 19,074,220$ & $18.99 \%$ \\
$\$ 30,815,130$ & $1.90 \%$ \\
2,622 & $0.29 \%$
\end{tabular}

$\underline{\text { A verage } V \text { alue }}$

$\$ 427,990,200$

$\$ 70,980,430$

$\$ 207,825,600$

12,007

A verage $V$ alue

$\$ \overline{5,052,218,000}$

$\$ 519,947,800$

$\$ 3,071,035,000$

114,320

\begin{tabular}{|c|}
\hline A verage Growth Rate \\
\hline $1.49 \%$ \\
\hline $2.45 \%$ \\
\hline $2.40 \%$ \\
\hline $0.90 \%$ \\
\hline
\end{tabular}

A verage Growth Rate $3.45 \%$

$3.61 \%$

$3.71 \%$

$1.86 \%$

Note: Real Values are in 2000 dollars. 
Table 7: Effects on Average Value Dependent Variables Resulting from Abandonment of $20 \%$ of County Rail Miles

\begin{tabular}{|c|c|c|c|c|c|c|}
\hline Rural & lead 1 & year 0 & $\operatorname{lag} 1$ & $\operatorname{lag} 2$ & $\operatorname{lag} 3$ & $\operatorname{lag} 4$ \\
\hline personal income (\$) & 0 & 0 & 0 & 0 & 0 & 0 \\
\hline transfer payments (\$) & 0 & $-142,675$ & $-212,868$ & 0 & 0 & 0 \\
\hline wage and salaries (\$) & 254,533 & 0 & 319,245 & 0 & 0 & $-452,982$ \\
\hline employment (\$) & 0 & 0 & 0 & 0 & 0 & 0 \\
\hline Urban & lead 1 & year 0 & $\operatorname{lag} 1$ & $\operatorname{lag} 2$ & $\operatorname{lag} 3$ & $\operatorname{lag} 4$ \\
\hline personal income $(\$)$ & 0 & 0 & 0 & 0 & 0 & 0 \\
\hline transfer payments (\$) & 0 & 0 & 0 & 0 & 0 & 0 \\
\hline wage and salaries (\$) & 0 & 0 & $1,043,285$ & 0 & $2,211,264$ & 0 \\
\hline employment (\$) & 0 & 0 & 0 & 0 & 73 & 0 \\
\hline Metropolitan & lead 1 & year 0 & $\operatorname{lag} 1$ & $\operatorname{lag} 2$ & $\operatorname{lag} 3$ & $\operatorname{lag} 4$ \\
\hline personal income (\$) & 0 & 0 & $104,783,001$ & 0 & $86,696,061$ & $-62,041,237$ \\
\hline transfer payments (\$) & 0 & 0 & 0 & $11,906,802$ & $13,955,396$ & 0 \\
\hline wage and salaries (\$) & 0 & 0 & 0 & 0 & 0 & 0 \\
\hline employment (\$) & 0 & 1,573 & 0 & 0 & 0 & 0 \\
\hline
\end{tabular}

$\$ 13,955,396$ in years two and three following the abandonment while the number of jobs in the county will increase by 1,573 at year zero.

The results of this analysis are surprising. It was theorized that econometric estimates would clearly indicate reductions in personal income, increases in transfer payments, reduced wages and salaries, and lost jobs. However, the results were mixed with only a few suggestions of adverse effects appearing with some time lag following an abandonment. If the growth effects predicted by economic theory are apparent, why are the adverse impacts predicted not as clearly evident?

There are some possible explanations for these results. First, the econometric estimates represent net effects and include both the adverse and beneficial impacts. Rail to truck diversion represents a shift to a more labor intensive transport mode, increasing the demand for local labor. This could explain why many of the coefficients indicate positive effects. In addition, the decreases in rail mileages throughout the state have been coincident with, if not related to, growth in the number of large transshipment facilities. Thus, economic declines at small country elevators are more than offset by growth at larger terminals.

Another explanation may be that, for production in Kansas, the elasticity of transport demand with respect to price is very low because transport costs are a relatively small portion of total production costs. As a result, many abandonment-related coefficients are non-significant.

Time may also be a factor. Adverse impacts may appear over a much longer period of time than the six-year adjustment period examined in this study. This may be due to the nature of the fixed capital investments involved.

Last, in many instances, the magnitude of abandonment-related effects may be small enough relative to the size of the local economy that the effects were not captured by the econometric estimates.

\section{CONCLUSIONS AND FUTURE STUDY}

This paper outlined economic theory that predicts a wide range of abandonment-related effects at the county level: effects on the prices of goods and services, factor payment levels, production decisions, income and related measures, and wealth. The econometric models produced interesting results, but the coefficients for abandonment-related variables were not all as expected. Only a few statistically significant abandonment variable coefficients were found, and any adverse impacts appear to be minimal. On the other hand, coefficients for the nonabandonment related variables often had the signs and magnitudes that were expected. Results indicate that population growth has the strongest effects on economic measures at the county level followed by regional product growth. 
Though the number of significant abandonment variable coefficients found was small, the results do provide some validation for the economic theory of abandonments. The significant abandonment coefficients suggest that abandonments are initially followed by net growth, some of which is temporary in some instances, and they may suggest that adverse effects appear with a time lag of a number of years.

The results of this analysis indicate several directions for future study. First, estimates suggest that adverse impacts may take a relatively long time to become manifest, and future studies using econometric techniques should examine abandonment related effects over a longer period of time.
This study examined the effects of abandonments on personal income, transfer payments, wages and salaries, and employment. Future studies using econometric techniques should examine other, possibly more direct, effects such as changes in local prices. Theory predicts that the prices paid for grain at local elevators, the prices of goods like fertilizer, and factor payments will be affected by abandonments. Effects on these prices may be more apparent with the use of econometric techniques.

Future studies should also look at effects on county wealth measures. For example, a study of real-estate values over a long-term period following abandonment would provide one indication of the long-run effects on county wealth levels.

\section{Endnote}

1. In 2003, maintenance of way, structures, and equipment accounted for $41.8 \%$ of operating expense (Association of American Railroads, 2004, p. 15).

\section{References}

Association of American Railroads (AAR). Yearbook of Railroad Facts. 1978 Edition, p. 47.

Association of American Railroads (AAR). Railroad Facts. 2004 Edition, p. 46.

Babcock, Michael W. and James L. Bunch. Impact of Grain Transportation on Kansas Highway Damage Costs. Topeka, Kansas Department of Transportation, 2002.

Babcock, Michael W., James L. Bunch, James Sanderson, and Jay Witt. "Impact of Short Line Railroad Abandonment on Highway Damage Costs: A Kansas Case Study.” Journal of the Transportation Research Forum published in Transportation Quarterly 57(4), (2003): 105-121.

Baltagi, Badi H. Econometric Analysis of Panel Data. Second Edition, John Wiley \& Sons, LTD, New York, 2001.

Bitzan, John D. and Denver D. Tolliver. "The Impacts of an Industry Switch to Large Rail Grain Hopper Cars on Local Infrastructure.” Journal of the Transportation Research Forum published in Transportation Quarterly 57(2), (2003): 135-154.

Bitzan, John D. and Denver D. Tolliver. Heavier Loading Rail Cars. MPC Report No. 01-127.2, Upper Great Plains Transportation Institute, North Dakota State University, Fargo, ND, 2001.

Brown, David L., Fred K. Hines, and John M. Zimmer. Social and Economic Characteristics of the Population in Metro and Nonmetro Counties: 1970. U.S. Department of Agriculture, Economic Research Service, 1970. 
Casavant, Kenneth L. and J.C. Lenzi. "Preparing for Rail Line Abandonment: Prediction of Financial and Locational Impacts on Roads.” Journal of the Transportation Research Forum 30, (1990): 264-274.

Chow, Ming H., Michael W. Babcock, and L. Orlo Sorenson. "The Changing Logistics Structure for Grain Marketing: A Case Study of Export Wheat in Northwest Kansas.” Transportation Journal 24(3), (1985): 37-46.

Eriksen, Kenneth and Kenneth L. Casavant. "Impact of Increased International Trade (NAFTA) on Washington Highways: Part II: Highway Impact By Corridor.” Eastern Washington Intermodal Transportation Study Research Report Number 25, Washington State Department of Transportation, 1998.

Eusebio, V.E. and Rindom, S.J. "Methodology for Estimating Road Damage Cost Resulting from Potential Rail Branch Line Abandonment: The Case of South Central Kansas.” Transportation Research Record No. 1305, (1991).

Eusebio, Victor E., Stephen J. Rindom, and Ali Abderrezak. "Economic Impacts of Rail Line Abandonment on Rural Communities in Kansas.” Rail Affairs Unit, Kansas Department of Transportation, Topeka, KS, 1992.

Federal Highway Administration. 1997 Federal Highway Cost Allocation Study Final Report. Washington D.C., 2000.

Forkenbrock, David J. “External Costs of Intercity Truck Freight Transportation.” Transportation Research Part A 33, (1999):505-526.

Griffin, Gene C. "Highway User Fees.” UGPTI Staff Paper No. 33, Upper Great Plains Transportation Institute, North Dakota State University, Fargo, ND, 1982.

Kansas Agricultural Statistics Service. Kansas Farm Facts. Topeka, Kansas State Board of Agriculture (1998, 1999, and 2000).

Kansas Department of Transportation (KDOT). “2002 Official Kansas State Railroad Map.” Topeka, Prepared by the Office of the Kansas Corporation Commission (2002a).

Kansas Department of Transportation, Bureau of Transportation Planning. "2003 - 2004 Official Transportation Map.” Topeka, KS, 2003.

Kansas Department of Transportation, Bureau of Planning, Rail Affairs Unit. Kansas Rail Plan Update 2000 - 2001. Topeka, KS, 2002.

Lenzi, J.C., Eric Jessup, and Kenneth L. Casavant. "Prospective Estimates for Road Impacts in Eastern Washington From a Drawdown of the Lower Snake River.” Eastern Washington Intermodal Transportation Study Working Paper Number 2, Washington State Department of Transportation, 1996.

Public Interest Economics Center (PIE-C). "Community Impact of Abandonment of Railroad Service.” Washington D.C., Prepared for the U.S. Railway Association, 1974. 
Rindom, Stephen J., John J. Rosacker, and Michael Wulfkuhle. “The Transportation Impact of Grain Subterminals in Kansas.” Kansas Department of Transportation, Bureau of Rail Affairs, Topeka, KS, 1997.

Russell, Eugene R., Michael W. Babcock, and Curtis Mauler. “A Methodology for Determining Road Damage Due to Railroad Branchline Abandonment.” 1996 Semi-sequicentennial Transportation Proceedings. Iowa Department of Transportation, Ames, IA, 1996.

Russell, Eugene R., Michael W. Babcock, and Curtis Mauler. "Study of the Impact of Rail Abandonment on Local Roads and Streets.” Conference Proceedings, Sixth International Conference on Low Volume Roads, Volume I (1995): 110-119.

Tolliver, Denver D. “The Impacts of Grain Subterminals on Rural Highways Volume I.” UGPTI Publication No. 74, North Dakota State University, Fargo, ND, 1989 a.

Tolliver, Denver D. “The Impacts of Grain Subterminals on Rural Highways Volume II.” UGPTI Publication No. 75, North Dakota State University, Fargo, ND, 1989 b.

Tolliver, Denver D., John Bitzan, Brian Lindamood, and Martha Struthers. “An Analysis of Light -Density Rail Lines in North Dakota.” UGPTI Publication No. 87, Upper Great Plains Transportation Institute, North Dakota State University, Fargo, ND, 1991.

Tolliver, Denver and HDR Engineering Inc. "Benefits of Rail Freight Transportation in Washington: A Multimodal Analysis.” Washington State Department of Transportation, 2000.

Tolliver, Denver, K. Andres, and B. Lindamood. "Washington Rail Impact Analysis: Executive Summary.” Washington State Department of Transportation, 1994.

U.S. Department of Commerce. Regional Economic Information System 1969-2001. Washington D.C. Bureau of Economic Analysis Economics and Statistics Administration, 2003.

U.S. Geologic Survey (USGS). Digital Raster Graphics (DRG) Collars Removed - NAD 83 Tiled by County. 8-22-1997, available at the Kansas Data Access and Support Center, http//gisdasc kgs. ukans.edu/.

Wilson, Rosalyn A. Transportation in America. Eno Transportation Foundation Inc., Washington, D.C., 2002.

James Sanderson received a B.A. degree in business administration in 1994 from Kansas Wesleyan University, an M.B.A. degree from Kansas State University in 1997, and an M.A. degree in economics also from Kansas State University in 2004. James has co-authored four professional journal articles, and was co-investigator on government research projects involving \$280,000 in research grant funding. James is currently senior research economist at the Kansas Corporation Commission where he conducts research and writes public testimony in dockets before the commission.

Michael W. Babcock is a professor of economics at Kansas State University (KSU). In his 30year career at KSU, he has published 70 articles in professional journals, along with numerous monographs and technical reports, and his research has been cited in more than 70 books, the transportation press, and technical journals. He has presented 70 papers at professional meetings, 
and he was principal investigator or co-investigator on 29 federal and state government research grants worth a total of more than $\$ 1.8$ million. Babcock is recognized as a leading national and international authority in three research areas including shortline railroad transportation; agricultural transportation; and impact of public policy on transportation market shares.

He has received numerous national awards for his transportation research. He has been recognized five times by the Transportation Research Forum for outstanding research in transportation economics. In addition, Babcock has received the Edgar S. Bagley Award four times from the KSU Department of Economics for outstanding achievement in transportation economics research. In 1999 he was awarded the ISBR Senior Faculty Award for Research Excellence in the Social and Behavioral Sciences from KSU. In 2005 he received the Herbert O. Whitten TRF Service Award for professional contributions to TRF. 